\title{
Usefulness of Agarose Mold as a Storage Container for Three-Dimensional Tissue-Engineered Cartilage
}

\author{
Yoshiyuki Mori ${ }^{1}$, Sanshiro Kanazawa ${ }^{2,3}$, Makoto Watanabe ${ }^{2,3}$, Hideyuki Suenaga ${ }^{1}$, Kazumi Okubo $^{{ }^{*}}$, \\ Satoru Nagata $^{4}$, Yuko Fujihara ${ }^{2,3}$, Tsuyoshi Takato ${ }^{1,2}$, Kazuto Hoshi ${ }^{1,2,3}$ \\ ${ }^{1}$ Department of Sensory and Motor System Medicine, Graduate School of Medicine, The University of Tokyo, Tokyo, Japan; \\ ${ }^{2}$ Department of Cartilage \& Bone Regeneration (Fujisoft), Graduate School of Medicine, The University of Tokyo, Tokyo, Japan; \\ ${ }^{3}$ Division of Tissue Engineering, The University of Tokyo Hospital, Tokyo, Japan; ${ }^{4}$ NAGATA Microtia and Reconstructive Plastic \\ Surgery Clinic, Saitama, Japan. \\ Email: pochi-tky@umin.net
}

Received July $4^{\text {th }}, 2013$; revised August $1^{\text {st }}, 2013$; accepted August $10^{\text {th }}, 2013$

Copyright (C) 2013 Yoshiyuki Mori et al. This is an open access article distributed under the Creative Commons Attribution License, which permits unrestricted use, distribution, and reproduction in any medium, provided the original work is properly cited.

\begin{abstract}
The efficiency of substance exchange may be decreased when the thickness and volume of such a tissue-engineered cartilage that is composed of cultured cells and porous scaffold increase. Moreover, during the transport of this construct with complicated shapes, excessive and focal mechanical loading may cause deformation. The establishment of incubation and transport methods is necessary for the three-dimensional tissue-engineered cartilage. Therefore, we investigated the preparation of an agarose mold with a concavity similar to the shape of 3-dimensional tissue-engineered cartilage to prevent excessive and focal concentration of stress, while avoiding interference with substance exchange as much as possible. Firstly, we investigated the preparation at $1 \%-4 \%$ agarose concentrations. Since the mechanical strength was insufficient at $1 \%, 2 \%$ was regarded as appropriate. Using $2 \%$ agarose, we prepared a mold with a $5 \times 5 \times$ $5 \mathrm{~mm}$ concavity to accommodate tissue-engineered cartilage $\left(5 \times 5 \times 5 \mathrm{~mm}\right.$ mixture of $1.5 \times 10^{7}$ cells and collagen gel $)$, and stored the regenerative cartilage in it for 2 and 24 hours. On comparison with storage in a plastic mold with the same shape in which substance exchanged from side and bottom was impossible, although no significant differences were noted in the number or viability of cells after 2 hours, these were markedly reduced in the plastic mold after 24 hours. It was confirmed that favorable cell numbers and viability were maintained by immediately retaining the regenerative cartilage in the culture medium in the agarose mold and keeping the temperature at $37^{\circ} \mathrm{C}$. Since this agarose mold also buffers against mechanical forces loaded on the three-dimensional regenerative tissue, it may be useful as a container for storage and transport of large-sized three-dimensional regenerative tissue.
\end{abstract}

Keywords: Tissue Engineering; Cartilage; Container; Storage; Transport

\section{Introduction}

Research and development of regenerative medicine are progressing for various organs [1]. The clinical application of cartilage regenerative medicine has particularly progressed, and a treatment method for cartilage defects involving injecting a gelatinous mixture or a cell suspension has already been clinically applied [2,3]. However, its application is limited to local articular defects or silicon removal after cosmetic surgery of the nose. We introduced a porous material of scaffold and succeeded in the development of tissue-engineered cartilage with a three-dimensional shape and mechanical strength $[4,5]$. Briefly, we regenerate cartilage with atelocollagen hy-

"Corresponding author. drogel and a PLLA porous scaffold used as a composite scaffold and apply it for treatment of nasal deformation in patients with cleft lip and palate [6]. The thickness, length, and width of this regenerated cartilage were 3 $\mathrm{mm}, 5 \mathrm{~cm}$, and $6 \mathrm{~mm}$, respectively, making it larger than previous regenerative cartilage. For this large-sized regenerative tissue prepared with the porous material, techniques of incubation containing cells with a higher density in the end-product and its transport to an operation theater are necessary. However, the efficiency of substance exchange is quite low in such a large-sized regenerative tissue, and central necrosis occurs [7]. In addition, a shape that fits specific regenerative tissue should be given to the storage container because such a construct prepared with a porous material has a complex 
shape simulating the human body.

Thus, we focused on agarose, which is used for general biological experiments. Agarose can be readily obtained, sterilized, and purchased cheaply, being very advantageous. Agarose is a plant-derived glycoprotein, and once it is gelled, it has very low adhesiveness to mammalian cells and very little biological influence on the regenerative tissue $[8,9]$.

As it is used as a matrix of electrophoresis, substance diffusibility is favorable, which is advantageous for the storage and culture of regenerative tissue containing abandant cells. In addition, since its gelation properties are marked, the liquid phase can be converted to the gel phase without changing the shape by temperature adjustment during culture and transport, which enables the preparation of a mold with a concavity fitting the shape of regenerative tissue. Mechanical forces loaded on regenerative tissue can be dispersed and reduced using this concave mold. We decided to prepare a mold for regenerative tissue using agarose with the various advantages described above, and use it for culture and transport. In the present study, to investigate the actual usefulness of this agarose mold for the culture and transport of regenerative tissue, we optimized the agarose mold, actually used it for the culture of tissue-engineered cartilage under various conditions, and evaluated the cell properties in the regenerative cartilage. An agarose concentration providing sufficient mechanical strength while allowing smooth substance exchange was established, and agarose molds were prepared at this concentration and used for the culture and storage of regenerative cartilage. The behavior of chondrocytes contained in the regenerative cartilage was evaluated, and the usefulness of the agarose mold was finally investigated.

\section{Materials and Methods}

\subsection{Preparation of Agarose Mold}

Agarose (Takara Bio, Otsu, Japan) was used. Agarose was mixed with MEM at a concentration of $1 \%-4 \%$, dissolved at $121^{\circ} \mathrm{C}$, and agarose fragments with a $15-\mathrm{mm}$ diameter and $5-\mathrm{mm}$ height were prepared at room temperature. To prepare agarose molds, $6 \mathrm{~mL}$ of autoclaved agarose solution was added to a 6 -well plate (BD, Carlsbad, USA) to create $5 \times 5 \times 5$-mm concavities. For comparison, $5 \times 5 \times 5$-mm plastic molds (Simport, Beloil, Canada) were used.

\subsection{Isolation and Analysis of Chondrocytes}

After obtaining informed consent, the perichondrium was detached from about $2-3 \mathrm{~g}$ of residual auricular cartilage surgically excised from a microtia patient. The cartilage was cut into $1-\mathrm{mm}^{3}$ pieces using a scalpel and incubated in $0.15 \%$ collagenase solution at $37^{\circ} \mathrm{C}$ for 24 hours with shaking in a thermostat [10]. The lysate was filtered through a cell strainer with a pore size of $100 \mu \mathrm{m}$ to remove residues, and then centrifuged at $500 \times \mathrm{g}$ for 5 minutes to isolate human chondrocytes. The isolated chondrocytes were seeded in a collagen type I-coat plastic tissue culture dish at a density of 2500 cells $/ \mathrm{cm}^{2}$, and cultured in chondrocyte growth medium (DMEM/F-12 containing $5 \%$ human serum, $100 \mathrm{ng} / \mathrm{mL}$ FGF-2, and 5 $\mu \mathrm{g} / \mathrm{mL}$ insulin) $[11,12]$ in a $37^{\circ} \mathrm{C} / 5 \% \mathrm{CO}_{2}$ incubator. The medium was changed twice a week. Cells were treated with trypsin-EDTA solution and passaged before reaching confluence. After 2 passages, cells were collected and subjected to experiments.

Human auricular chondrocytes and 3\% atelocollagen gel (KOKEN, Tokyo, Japan) were mixed, adjusting the cell concentration to $1.0 \times 10^{8}$ cells $/ \mathrm{ml}$ and gel concentration to $1 \%$ as regenerative cartilage $[4,13]$.

\subsection{Evaluation Method}

The mechanical strength was measured using Venustron (Axiom, Fukushima, Japan). Under computer control, the motor-driven sensor unit automatically presses down on the surface of the materials and provides an indentation force and a decrease in the resonant frequency. The resonant frequency of the sensor was set to $50 \mathrm{~Hz}$, while the maximum depth of indentation was $1 \mathrm{~mm}$. Young's modulus can be calculated by the indentation force and the decrease in the resonant frequency, based on the principles previously reported $[14,15]$. It was measured 5 times, and the mean and standard deviation were calculated. For measurements of the cell properties, the sample was treated with $8 \mathrm{~mL}$ of $0.3 \%$ collagenase at $37^{\circ} \mathrm{C}$ until collagen was digested (about 60 minutes), and the numbers of viable and dead cells, as well as cell vaibility, were determined using NucleoCounter (Chemometec, Gydevang, Denmark) [16].

\section{Results}

Firstly, the agarose concentration to prepare agarose molds was evaluated. One to four percent agarose gel was prepared, and the mechanical strength was measured. Young's modulus of agarose gel increased in a concentration-dependent manner, but the strength of $1 \%$ agarose gel was less than $100 \mathrm{kPa}$ and insufficient to retain the external shape. The strength of a $2 \%$ or higher agarose gel exceeded $200 \mathrm{kPa}$ and could retain the external shape (Figure 1). Considering that a low concentration is advantageous for substance diffusion, we adopted a $2 \%$ agarose concentration for agarose molds.

Agarose molds to retain regenerative cartilage were prepared using $2 \%$ agarose gel. In order to evaluate the usefulness of this agarose mold, we made the regenerative cartilage consisting of cultured chondrocytes $(1.5 \times$ 


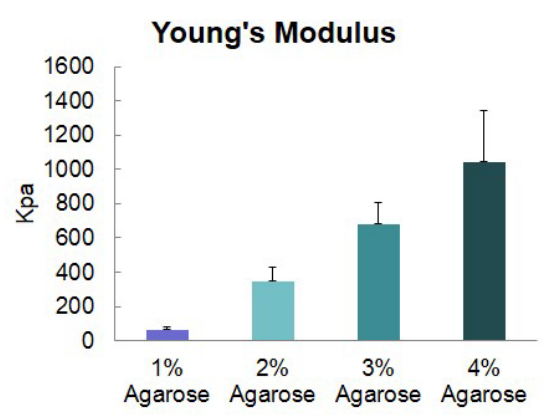

Figure 1. Mechanical strength of agarose. The strength of agarose gel increased in a concentration-dependent manner.

$10^{7}$ cells) and atelocollagen $(150 \mu \mathrm{L})$ : in the agarose mold in a humid bath (Figure 2, Group A), in the agarose mold and combined with medium (Figure 2, Group B), or in a plastic mold with no substance permeability in a humid bath (Figure 2, Group C) at $37^{\circ} \mathrm{C}$ for 2 hours. When the mechanical strength of the regenerative cartilage was measured, Young's modulus was about $20 \mathrm{kPa}$ in Groups A and B, but less than $10 \mathrm{kPa}$ in Group C (Figure 2 Young's modulus). On the other hand, the indentation force was about $2 \mathrm{~g}$ in all groups, showing no marked difference among the groups (Figure 2 Pressure), nor was there a marked decrease in the resonant frequency (Figure 2 Tactile).

The numbers of chondrocytes and the cell viability of the regenerative cartilages were measured. The number of administered cells was $1.5 \times 10^{7}$ cells. The total number of cells after 2-hour storage at $37^{\circ} \mathrm{C}$ was approximately $1.3 \times 10^{7}$ cells in all groups, showing no marked difference. The numbers of dead and viable cells and the cell viability were $6 \times 10^{5}, 1.2 \times 10^{7}$, and approximately $95 \%$, respectively, in all groups, showing no significant differences among the groups (Figure 3).

In each group, the molds were stored for another 22 hours in a humid bath at $37^{\circ} \mathrm{C}$ (Figure 4, Group H), combined with medium and stored at $37^{\circ} \mathrm{C}$ (Figure 4, Group $\mathrm{M}$ ), or in a humid bath at $4^{\circ} \mathrm{C}$ (Figure 4, Group L). The total number of cells markedly decreased in the groups both contained in the plastic mold and stored at $37^{\circ} \mathrm{C}$. The number of viable cells and the cell viability were lower in the groups contained in the plastic mold under all conditions. In the group contained in the agarose mold and combined with medium (Figure 4, Group B), the number of cells and the cell viability were still relatively favorable after 24 hours. In the group contained in the agarose mold and stored at $4^{\circ} \mathrm{C}$ (Figure 4, Group AL) and the group in the agarose mold, combined with medium, and stored at $37^{\circ} \mathrm{C}$ (Figure 4, Group B), approximately $80 \%$ of administered cells were retained after 24 hours, and the cell viablity was higher than $90 \%$, suggesting that these may be used as favorable storage conditions.


Figure 2. Mechanical strength of regenerated cartilage prepared using the agarose mold. Cultured human chondrocytes $(1.5 \times 107$ cells $)$ were mixed with $150 \mu \mathrm{L}$ of $1 \%$ atelocollagen and placed in the agarose $(A, B)$ and plastic $(C)$ molds to prepare regenerative cartilage. The regenerative cartilages prepared at $37^{\circ} \mathrm{C}$ for 2 hours: in the agarose mold (A), in the agarose mold with $2 \mathrm{~mL}$ of MEM (B), and in a plastic mold with no substance permeability (C), were compared. Young's modulus was calculated by indentation force (Pressure) and a decrease in resonant frequency (Tactile).

\section{Discussion}

In the present study, the agarose mold was used as a container to preserve and store regenerative tissue with an about $5-\mathrm{mm}$ thickness in which cells were present at a high density $\left(10^{8} / \mathrm{mL}\right)$. It was suggested that substance exchange can be maintained for 24 hours in the agarose mold, and cell viability in the tissue can be retained. In addition, the agarose mold stably holds the tissue- engi neered constructs and buffers physical impacts, which are very advantageous for the transport of vulnerable 



Figure 3. Cell properties after 2-hour culture of cartilage prepared using the agarose mold. Cultured human chondrocytes $(1.5 \times 107$ cells $)$ were mixed with $150 \mu \mathrm{L}$ of $1 \%$ atelocollagen and placed into the agarose $(\mathrm{A}, \mathrm{B})$ and plastic (C) molds to prepare regenerative cartilage. The regenerative cartilages were prepared at $37^{\circ} \mathrm{C}$ for 2 hours in the agarose mold (A), in the agarose mold with $2 \mathrm{~mL}$ of MEM (B), and in a plastic mold with no substance permeability (C). After 2 hours, the cells were treated with collagenase and collected, and the number and viability of cells were evaluated.

regenerative tissue before transplantation. Actually, it is becoming increasingly successful as a culture and transport container for the end-products of three-dimensional tissue-engineered cartilage tissue $(5 \mathrm{~cm} \times 6 \mathrm{~mm} \times 3 \mathrm{~mm})$ for delivery to operating theater (Figure 5) [6].

Regenerative tissue culture methods include the simple placement of tissue in a vessel with some culture medium. This method does not require a specific device and can be readily prepared, but the tissue may be damaged on contacting the vessel. Moreover, excessive shear stress may be loaded by the culture medium and negatively influence cells. Since the regenerative tissue before transplantation is very unstable, this method may be inappropriate.

Methods to overcome these problems have been proposed as the floating culture of regenerative tissue. It was reported that the large-sized tissue-engineered constructs were cultured, using roating wall vessel (RWV) [17].


Figure 4. Cell properties after 24-hour culture of cartilage prepared using the agarose mold. Cultured human chondrocytes $(1.5 \times 107$ cells $)$ were mixed with $150 \mu \mathrm{L}$ of $1 \%$ atelocollagen and placed into the agarose $(\mathrm{A}, \mathrm{B})$ and plastic (C) molds to prepare regenerative cartilage. The regenerative cartilages were prepared at $37^{\circ} \mathrm{C}$ for 2 hours in the agarose mold (A), in the agarose mold with $2 \mathrm{~mL}$ of $\mathrm{MEM}$ (B), and in a plastic mold with no substance permeability (C). In each group, the cartilage was retained in the mold for another 22 hours in a $37^{\circ} \mathrm{C}$ humid bath (H), with $2 \mathrm{~mL}$ of MEM at $37^{\circ} \mathrm{C}(\mathrm{M})$, or in a $4^{\circ} \mathrm{C}$ humid bath (L). The cells were treated with collagenase and collected, and the number and viability of cells were evaluated.

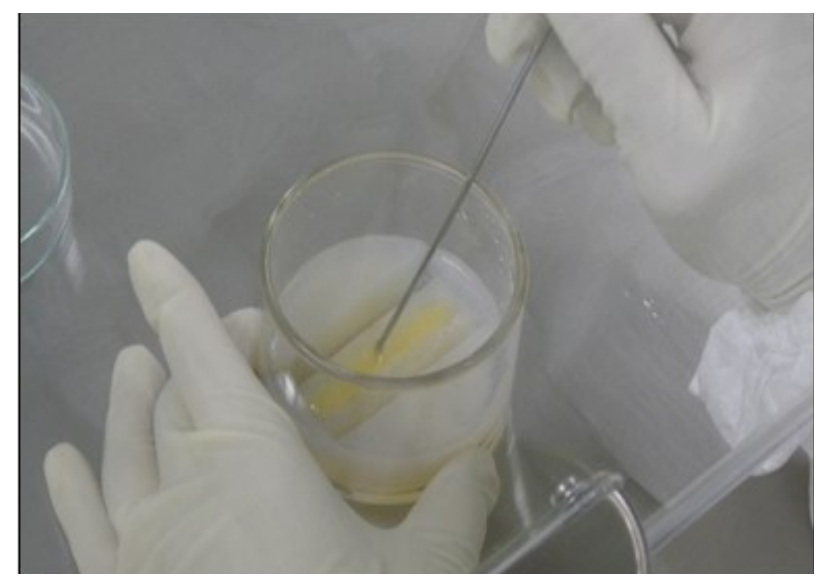

Figure 5. An agarose mold used for clinical application. Cartilage was regenerated for clinical application using the $2 \%$ agarose mold [6]. 
When the RWV was used to culture the mesenchymal stem cells, favorable results of cartilage regeneration have been found[18]. However, the floating culture requires specific devices, a problem remains with regard to transport, and, basically, only rounded shapes, such as spherical and circular shapes, can be used because mechanical forces can be spread out. Gyratory culture was also reported [19], but, similarly, tissue can be cultured only in rounded shapes. Thus, it is difficult to prepare tissue-engineered cartilage fitting the shape required, and these methods may be inapplicable.

Retention in medium with a mesh or cage is also considered. When tissue is fixed using a mesh or cage, mechanical stress may be concentrated on a specific region of a line or a point, and change the shape during transport or culture. Thus, fixation in culture medium using a mesh or cage may be basically difficult. As the mesh or cage may be processed adjusting it to the shape of regenerated tissue, it must be custom-made for individual cases, which is economically inefficient.

Thus, we investigated a material through which nutrition and oxygen are readily exchanged, such as hydrogel, with marked gelation properties, high mechanical strength, and flexibility to readily change shape, and prepared a hydrogel mold. For the material of hydrogel, we considered that with favorable substance exchangeability and minimum influence on tissue. There are various types of hydrogel [13], but we focused on agarose because it has marked gelation properties and weak cell-adhesive properties and toxicity [9].

Agarose is comprised of D-galactose bound at $\mathrm{C} 1$ and $\mathrm{C} 3$ and 3,6-unhydro-L-galactose bound at C1 and C4. These 2 types of sugar alternately bond, forming a repeat bonding neutral polysaccharide [9]. Agar was another choice. Agar is prepared by extracting mucilage from Rhodophyceae, mainly seaweeds of Gelidiaceae and Gracilaria, and removing water. The main components of agar are polysaccharides, and it is used as a material for agarose production. Agar for microbial culture matrix is also available, but it contains seaweed-derived minerals, crude proteins, and other contaminants, in addition to saccharides [8]. Thus, purer agarose is more readily used for regenerative medicine requiring strict quality control. This may be advantageous to retain regenerative medicine products.

In the plastic mold, no nutrient or oxygen may have diffused and waste may have accumulated, reducing viability. Substances can diffuse through the agarose mold, which may be very advantageous in structures for regenerative medicine containing cells at a high density. The causes of cell death include dryness, in addition to the inhibition of diffusion. Cells are very sensitive to dryness, and extracellular matrix-detached cells are readily exposed to dryness. When culture medium was added im- mediately after placing the tissue-engineered constructs, the cell viability was very high, although the survival rate was rather low when culture medium was added later. For atelocollagen mixed with cells as a base material of tissue regeneration, an acidic product was used [20]. The addition of a large volume of neural-buffered culture medium immediately after mixing cells with atelocollagen may have buffered the $\mathrm{pH}$ of atelocollagen and promoted cell survival. When the agarose mold was used with no culture medium, cell viability was superior in the tissue stored at $4^{\circ} \mathrm{C}$ to that at $37^{\circ} \mathrm{C}$, suggesting that a low temperature was advantageous to maintain humidity, preventing drying.

Regenerative medicine products to be introduced in medical care in the future will probably become larger and more complex, and therefore, culture and transport methods for these large regenerative tissues are essential for the generalization and advancement of regenerative medicine. We are actually using the mold for culture and storage of $5 \mathrm{~cm} \times 6 \mathrm{~mm} \times 3$-mm dome-shaped tissueengineered cartilage prepared with a porous material and atelocollagen [6]. It is necessary to develop a culture container with a higher substance exchange efficiency by accumulating experience and clinical data.

\section{Conclusion}

The agarose mold seemed useful as a container for storage and transport of large-sized three-dimensional regenerative tissue. Because this kind of mold is available for both culture and transport of the large regenerative tissues, it will contribute to for the generalization and advancement of regenerative medicine.

\section{Acknowledgements}

We thank Ms. Yuko Motoki and Mr. Tomoaki Sakamoto for technical support. This work was supported by Grantsin-Aid for Scientific Research from the Ministry of Education, Culture, Sports, Science and Technology of Japan (MEXT, No. 24390451, 24593050, and 25670847) and from the Ministry of Health, Labour and Welfare of Japan (MHLW, No. H24-Saisei-Ippan-005), and Research and Development Programs for Self-maturating Device from the New Energy and Industrial Technology Development Organization (NEDO).

\section{REFERENCES}

[1] J. A. Baddour, K. Sousounis and P. A. Tsonis, "Organ Repair and Regeneration: An Overview," Birth Defects Research C: Embryo Today, Vol. 96, No. 1, 2012, pp. 129. doi:10.1002/bdrc. 21006

[2] M. Ochi, Y. Uchio, K. Kawasaki, S. Wakitani and J. Iwasa, "Transplantation of Cartilage-Like Tissue Made by Tissue Engineering in the Treatment of Cartilage Defects 
of the Knee," The Journal of Bone \& Joint Surgery British, Vol. 84, No. 4, 2002, pp. 571-578. doi:10.1302/0301-620X.84B4.11947

[3] H. Yanaga, K. Yanaga, K. Imai, M. Koga, C. Soejima and K. Ohmori, "Clinical Application of Cultured Autologous Human Auricular Chondrocytes with Autologous Serum for Craniofacial or Nasal Augmentation and Repair," Plastic and Reconstructive Surgery, Vol. 117, 2006, pp. 2019-2030.

[4] H. Yamaoka, Y. Tanaka, S. Nishizawa, Y. Asawa, T. Takato and K. Hoshi, "The Application of Atelocollagen Gel in Combination with Porous Scaffolds for Cartilage Tissue Engineering and Its Suitable Conditions," Journal of Biomedical Materials Research Part A, Vol. 93, 2010, pp. 123-132.

[5] Y. Tanaka, H. Yamaoka, S. Nishizawa, S. Nagata, T. Ogasawara, Y. Asawa, Y. Fujihara, T. Takato and K. Hoshi, "The Optimization of Porous Polymeric Scaffolds for Chondrocyte/Atelocollagen Based Tissue-Engineered Cartilage," Biomaterials, Vol. 31, No. 16, 2010, pp. 45064516. doi:10.1016/j.biomaterials.2010.02.028

[6] K. Hoshi, Y. Fujihara, Y. Asawa, S. Nishizawa, S. Kanazawa, T. Sakamoto, M. Watanabe, T. Ogasawara, H. Saijo and T. Takato, "Recent Trends of Cartilage Regenerative Medicine and Its Application to the Oral and Maxillofacial Surgery," Oral Science International, Vol. 10, No. 1, 2013, pp. 15-19. doi:10.1016/S1348-8643(12)00049-3

[7] S. Sekiya, T. Shimizu and T. Okano, "Vascularization in 3D Tissue Using Cell Sheet Technology," Regenerative Medicine, Vol. 8, No. 3, 2013, pp. 371-377. doi: $10.2217 / \mathrm{rme} .13 .16$

[8] D. A. Rees, "Strucutre, Conformation, and Mechanism in the Formation of Polysaccaride Gels and Networks," Advances in Carbohydrate Chemistry \& Biochemistry, Vol. 24, 1969, pp. 267-332. doi:10.1016/S0065-2318(08)60352-2

[9] S. Arnott, A. Fulmer, W. E. Scott, I. C. Dea, R. Moorhouse and D. A. Rees, "The Agarose Double Helix and Its Function in Agarose Gel Structure," Journal of Molecular Biology, Vol. 90, No. 2, 1974, pp. 269-284. doi:10.1016/0022-2836(74)90372-6

[10] K. Yonenaga, S. Nishizawa, Y. Fujihara, Y. Asawa, S. Kanazawa, S. Nagata, T. Takato and K. Hoshi, "The Optimal Conditions of Chondrocyte Isolation and Its Seeding in the Preparation for Cartilage Tissue Engineering," Tissue Engineering Part C: Methods, Vol. 16, No. 6, 2010, pp. 1461-1469. doi:10.1089/ten.tec.2009.0597

[11] Y. Tanaka, T. Ogasawara, Y. Asawa, H. Yamaoka, S. Nishizawa, Y. Mori, T. Takato and K. Hoshi, "Growth Factor Contents of Autologous Human Sera Prepared by Different Production Methods and Their Biological Effects on Chondrocytes," Cell Biology International, Vol. 32, 2008, pp. 505-514. doi:10.1016/j.cellbi.2007.12.012

[12] T. Takahashi, T. Ogasawara, J. Kishimoto, G. Liu, H. Asato, T. Nakatsuka, E. Uchinuma, K. Nakamura, H. Kawaguchi, T. Takato and K. Hoshi, "Synergistic Effects of FGF-2 with Insulin or IGF-I on the Proliferation of Human Auricular Chondrocytes," Cell Transplant, Vol. 14, No. 9, 2005, pp. 683-693. doi: $10.3727 / 000000005783982675$

[13] H. Yamaoka, H. Asato, T. Ogasawara, S. Nishizawa, T. Takahashi, T. Nakatsuka, I. Koshima, K. Nakamura, H. Kawaguchi, U. I. Chung, T. Takato and K. Hoshi, "Cartilage Tissue Engineering Using Human Auricular Chondrocytes Embedded in Different Hydrogel Materials," Journal of Biomedical Materials Research Part A, Vol. 78, No. 1, 2006, pp. 1-11. doi:10.1002/jbm.a.30655

[14] R. Aoyagi and T. Yoshida, "Freuqency Equations of an Ultrasonic Vibrator for the Elastic Sensor Using a Contact Impedance Method," Japanese Journal of Applied Physics, Vol. 5B, 2004, pp. 3204-3209. doi:10.1143/JJAP.43.3204

[15] Y. Kang, J. Yang, S. Khan, L. Anissian and G. A. Ameer, "A New Biodegradable Polyester Elastomer for Cartilage Tissue Engineering," Journal of Biomedical Materials Research Part A, Vol. 77, No. 2, 2006, pp. 331-339. doi:10.1002/jbm.a.30607

[16] K. Yonenaga, S. Nishizawa, M. Akizawa, Y. Asawa, Y. Fujihara, T. Takato and K. Hoshi, "Utility of NucleoCounter for the Chondrocyte Count in the Collagenase Digest of Human Native Cartilage," Cytotechnology, Vol. 62, 2010, pp. 539-545. doi:10.1007/s10616-010-9304-y

[17] Y. Ohyabu, N. Kida, H. Kojima, T. Taguchi, J. Tanaka and T. Umemura, "Cartilaginous Tissue Formation from Bone Marrow Cells Using Rotating Wall Vessel (RWV) Bioreactor," Biotechnology and Bioengineering, Vol. 95, No. 5, 2006, pp. 1003-1008. doi:10.1002/bit.20892

[18] S. Sakai, H. Mishima, T. Ishii, H. Akaogi, T. Yoshioka, Y. Ohyabu, F. Chang, N. Ochiai and T. Umemura, "Rotating Three-Dimensional Dynamic Culture of Adult Human Bone Marrow-Derived Cells for Tissue Engineering of Hyaline Cartilage," Journal of Orthopaedic Research, Vol. 27, No. 4, 2009, pp. 517-521. doi:10.1002/jor.20566

[19] K. S. Furukawa, H. Suenaga, K. Toita, A. Numata, J. Tanaka, T. Ushida, Y. Sakai and T. Tateishi, "Rapid and Large-Scale Formation of Chondrocyte Aggregates by Rotational Culture," Cell Transplant, Vol. 12, 2003, pp. 475-479.

[20] C. Cohen, "Optical Rotation and Helical Polypeptide Chain Configuration in Collagen and Gelatin," Journal of Biophysical and Biochemical Cytology, Vol. 1, No. 1, 1955, pp. 203-214. doi:10.1083/jcb.1.3.203 